\title{
A Case of Gastroesophageal Cancer after Laparoscopic Sleeve Gastrectomy
}

\author{
Ahmad A. Aljarboo ${ }^{1 *}$, Faisal Alghamdi ${ }^{1}$, Abdullah Alzahrani ${ }^{1}$, Bandar Ali ${ }^{1}$
}

'Department of General Surgery, Prince Sultan Military Medical City, Riyadh, Saudi Arabia.

\section{To Cite}

Aljarboo A. A, Alghamdi F, Alzahrani A, Ali B. A Case of Gastroesophageal Cancer after Laparoscopic Sleeve Gastrectomy. J Gastric Surg 2020; 2(4).

\section{Publication history}

Received: September 29, 2020

Accepted: October 01, 2020

Article in press: October 02, 2020

Published online: October 05, 2020

\section{*Correspondence to}

Ahmad A. Aljarboo, MD

Department of General Surgery

Prince Sultan Military Medical City

Makkah Al Mukarramah Rd, As Sulimaniyah 12233, Riyadh, Saudi Arabia.

ahmadaljarboo@gmail.com

\begin{abstract}
Gastric cancer has been reported in relatively few cases after sleeve gastrectomy, which has become a common bariatric procedure. In this paper, we present a 58-year-old woman diagnosed with gastric cancer by esophagogastroduodenoscopy (EGD) 4 years after sleeve gastrectomy. For that, she underwent distal esophagectomy and total gastrectomy with Roux-en-Y esophagojejunostomy. Preoperative endoscopy is recommended before planning surgery in patients with gastroesophageal reflux symptoms. In addition, annual EGD should be considered after sleeve gastrectomy in patients with risk factors for gastric cancer.
\end{abstract}

Keywords:

Bariatric surgery, gastric cancer, sleeve gastrectomy. 


\section{Background}

Obesity is a major cause of morbidity and mortality worldwide, including its reported risk for causing esophageal and gastric cancer.[1, 2] Bariatric surgery, in general, offers an efficient solution to reducing weight, with non-surgical therapy being ineffective in a large number of cases. Sleeve gastrectomy is a widely used procedure, with possible reported complications such as leakage, strictures, bleeding, nutrient deficiency, and gastroesophageal reflux disease (GERD).[3] However, relatively few cases of gastric adenocarcinoma postsleeve gastrectomy were reported (to the best of our knowledge, 7 cases have been reported in English literature).

\section{Case Report}

The patient is a 58-year-old woman known to have hypertension, hypothyroidism, bronchial asthma, rheumatoid arthritis, and a history of GERD. She denied having a family history of gastrointestinal (GI) malignancy, and she has no history of smoking. She underwent laparoscopic sleeve gastrectomy in April 2016 in another institution; at that time, she had a body mass index (BMI) of $52 \mathrm{~kg} / \mathrm{m} 2$. In October 2017, the patient presented with failure to reduce her weight beyond a BMI of $42 \mathrm{~kg} / \mathrm{m} 2$. An esophagogastroduodenoscopy (EGD) was performed due to symptoms of GERD and iron deficiency anemia and showed a moderate hiatal hernia with mild reflux esophagitis (grade A, Los Angeles classification). In addition, a biopsy was taken from the patient's stomach, which showed chronic gastritis with the presence of Helicobacter pylori (H. Pylori) and no dysplasia or malignancy. The patient received treatment of H. Pylori and revisional surgery and hiatal hernia repair was planned to control her symptoms and her weight, but the procedure was not completed due to a long waiting list.

In January 2020, the patient underwent EGD due to progressive mild dysphagia to solid and liquid food over 4 months, which showed an ulcerated polypoid mass at the gastroesophageal junction $35 \mathrm{~cm}$ from the incisors, with the rest of stomach and duodenum showing normal mucosa (Figure 1).
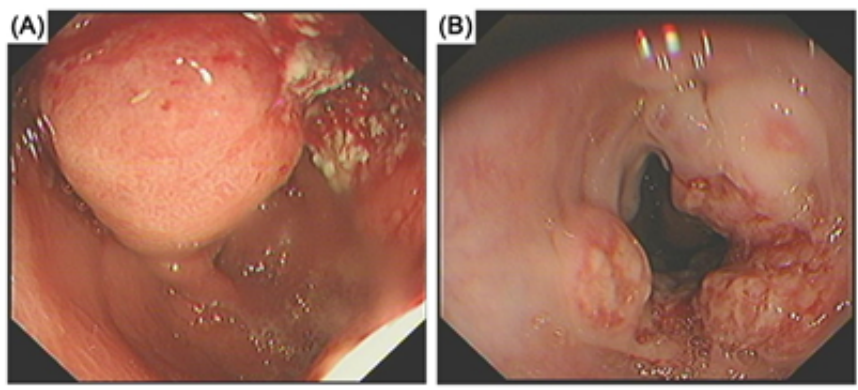

Figure 1: EGD showing polypoid mass on the gastroesophageal junction (A) with ulceration shown along the gastroesophageal junction (B).

A biopsy from the mass showed invasive moderately differentiated adenocarcinoma. The tumor markers were alpha-fetoprotein (AFP) $<0.75 \mathrm{ng} / \mathrm{mL}$, carcinoembryonic antigen (CEA) $3.5 \mathrm{ng} / \mathrm{mL}$, carbohydrate antigen (CA-125) $13 \mathrm{U} / \mathrm{mL}$, and carcinoid antigen (CA19-9) $57 \mathrm{U} / \mathrm{mL}$. Staging computed tomography for the chest, abdomen, and pelvis (CT
CAP) and positron emission tomography (PET-CT) showed hypermetabolic polypoid circumferential thickening involving the known herniated stomach with extension into the gastroesophageal junction associated with multiple gastrohepatic and left para-aortic lymphadenopathy (Figure 2).
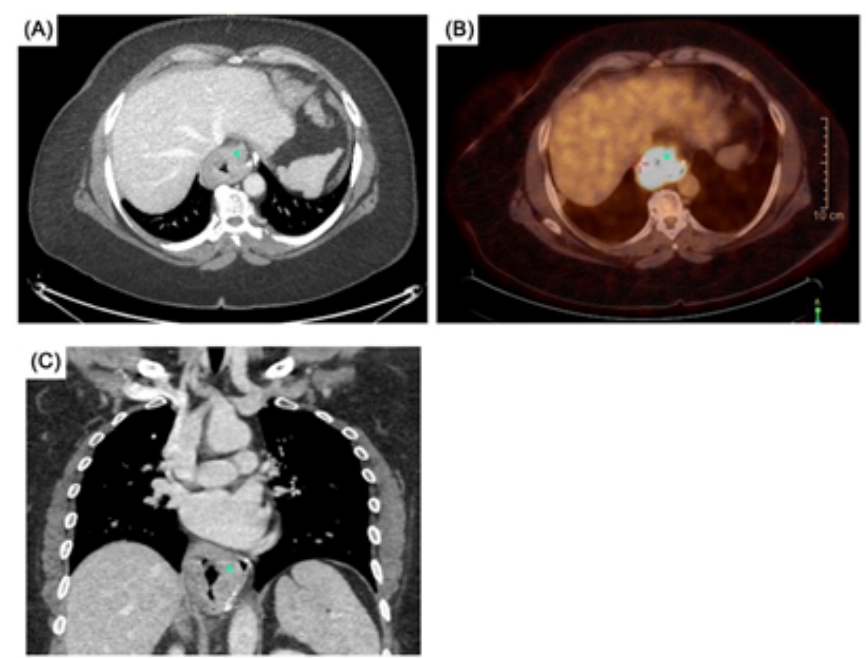

Figure 2: (A) Axial view of CT chest with asterisk showing the cancer, (B) PET-CT with asterisk showing the cancer with hypermetabolic activity, (C) Coronal view of CT chest with asterisk showing the cancer with hiatal hernia noted.).

The patient was taken for diagnostic laparoscopy with peritoneal lavage for staging, where the tumor was seen at the cardia of the stomach up to the gastroesophageal junction, with great omentum seeding visualized. A biopsy was taken, and the solid organs were intact with no ascites. The biopsy from the omental seeding showed no evidence of metastatic carcinoma. The cytology report from the peritoneal fluid showed scattered atypical cells and mucin, with degenerated mesothelial cells in a background of lymphocytes and red blood cells, which are signs of malignancy. The case was discussed during the multidisciplinary tumor board meeting, which planned for neoadjuvant chemotherapy. The patient started in 4 cycles (5-Fluorouracil, Leucovorin, Oxaliplatin, and Docetaxel) for approximately 8 weeks. The follow up after chemotherapy with PET-CT showed almost complete resolution of the mass with only mild gastroesophageal thickening showing minimal metabolic activity (Figure 3).

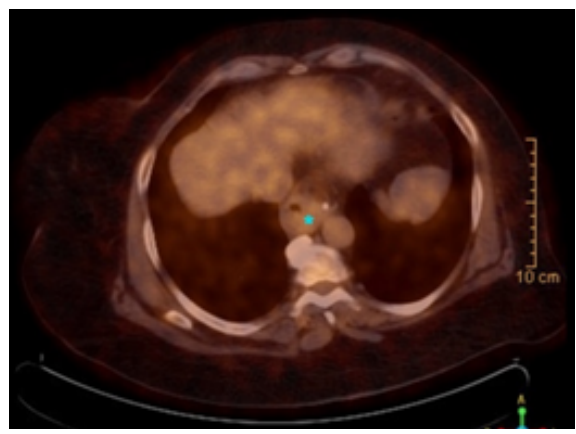

Figure 3: PET-CT, with asterisk showing almost complete resolution of the previously seen hypermetabolic gastroesophageal junction mass.

In June 2020, the patient underwent surgery, distal esophagectomy, and total gastrectomy with Roux-en- $Y$ esophagojejunostomy and saw an uneventful recovery. 
Final pathological staging (pT2 N1M0) showed no lymphovascular or perineural invasion, and all surgical margins were free.[4] The patient was discharged on day 11 post operation, after ensuring no leaks via an upper GI study.

\section{Discussion}

Gastric cancer is uncommon in Saudi Arabia.[5] Its incidence is decreasing worldwide due to the early detection and eradication of H.pylori infection, which is one of the most common independent risk factors. [6] In addition, there are multiple environmental and genetic factors. Hiatal hernia and GERD are considered significant risk factors for esophageal and gastric cardia adenocarcinoma, with an increase in fold when combined.[7] Nowadays, preoperative EGD is performed routinely before planning any bariatric surgery in our institution, although it is still debated and selective in many studies.[8] It is important to check for signs of gastritis, H.pylori, and dysplasia or masses before surgery, especially before gastric bypass since the patient's anatomy will be disturbed. Interestingly, there are reported cases of gastric cancer diagnosed after sleeve gastrectomy. Two cases have been reported to have GERD, which was the only underlying risk factor. $[9,10]$ Another two patients were known to have hiatal hernia, which was repaired during the sleeve gastrectomy.[11, 12] However, there was no H.pylori detected in those cases. The resected stomach during planned bariatric surgery is sent for histopathology in some cases and is typically unremarkable.[13] In this case, there were multiple risk factors, including H.pylori infection, which was treated, hiatal hernia, persistent GERD, and obesity. There was an interval between the two EGDs done after the surgery, which could give rise to further degeneration. Another interesting aspect is to consider sending the resected stomach during sleeve gastrectomy for histopathology in such patients, as they are considered high risk.[14] It is worth pointing out that post-operative EGD might be necessary in high-risk patients, and it should be done annually after to detect any dysplasia or masses.[15]

\section{Acknowledgements \\ None}

\section{Contributors}

AAA, FA, AA, BA conceptualized and designed the study, acquired, and analyzed data, interpreted the study results, drafted the manuscript, and critically revised the final version of the manuscript.

\section{Funding}

No funding was received for this study.

\section{Competing interests}

No benefits in any form have been received or will be received from a commercial party related directly or indirectly to the subject of this article.

\section{Availability of data and materials}

Further information is available from the corresponding author on reasonable request.
Ethics approval

Not applicable.

\section{Provenance and peer review}

Not commissioned; externally peer reviewed.

\section{Open access}

This is an Open Access article distributed in accordance with the Creative Commons Attribution NonCommercial (CC BY-NC 4.0) license, which permits others to distribute, remix, adapt, build upon this work noncommercially, and license their derivative works on different terms, provided

the original work is properly cited and the use is non-commercial. See: http://creativecommons.org/ licenses/by-nc/4.0/

\section{References}

[1] Scozzari G, Trapani R, Toppino M, Morino M. Esophagogastric cancer after bariatric surgery: systematic review of the literature. Surg Obes Relat Dis. 2013;9:133-42.

[2] Du X, Hidayat K, Shi BM. Abdominal obesity and gastroesophageal cancer risk: systematic review and meta-analysis of prospective studies. Biosci Rep. 2017;37.

[3] Sarkhosh K, Birch DW, Sharma A, Karmali S. Complications associated with laparoscopic sleeve gastrectomy for morbid obesity: a surgeon's guide. Can J Surg. 2013;56:347-52.

[4] Amin MB, Greene FL, Edge SB, Compton CC, Gershenwald JE, Brookland RK, et al. The Eighth Edition AJCC Cancer Staging Manual: Continuing to build a bridge from a population-based to a more "personalized" approach to cancer staging. CA Cancer J Clin. 2017;67:93-9.

[5] Abuderman AA. Gastric cancer \& prospects of cancer in Saudi Arabia peninsula. Saudi J Biol Sci. 2019;26:1095-100.

[6] Lee YC, Chiang TH, Chou CK, Tu YK, Liao WC, Wu MS, et al. Association Between Helicobacter pylori Eradication and Gastric Cancer Incidence: A Systematic Review and Meta-analysis. Gastroenterology. 2016;150:1113-24 e5.

[7] $\mathrm{Wu} \mathrm{AH}$, Tseng CC, Bernstein L. Hiatal hernia, reflux symptoms, body size, and risk of esophageal and gastric adenocarcinoma. Cancer. 2003;98:940-8.

[8] Parikh M, Liu J, Vieira D, Tzimas D, Horwitz D, Antony A, et al. Preoperative Endoscopy Prior to Bariatric Surgery: a Systematic Review and Meta-Analysis of the Literature. Obes Surg. 2016;26:29616

[9] Angrisani L, Santonicola A, Iovino P. Gastric cancer: a de novo diagnosis after laparoscopic sleeve gastrectomy. Surg Obes Relat Dis. 2014;10:186-7.

[10] Yamashita T, Tan J, Lim E, Eng A, Ong HS, Chan WH. A case of gastric cancer after sleeve gastrectomy. Asian J Endosc Surg. 2019.

[11] Vladimirov M, Hesse U, Stein HJ. Gastric carcinoma after sleeve gastrectomy for obesity. Surg Obes Relat Dis. 2017;13:1459-61.

[12] Masrur M, Elli E, Gonzalez-Ciccarelli LF, Giulianotti PC. De novo gastric adenocarcinoma 1 year after sleeve gastrectomy in a transplant patient. Int J Surg Case Rep. 2016;20:10-3.

[13] Sohn S, Fischer J, Booth M. Adenocarcinoma of the gastrooesophageal junction after sleeve gastrectomy: a case report. ANZ J Surg. 2017;87:E163-E4

[14] Angrisani L, Palma R, Santonicola A, Ferraro L, Iovino P. Sleeve Gastrectomy and Gastric Cancer: Is It Really Rare? Obes Surg. 2020;30:4119-21.

[15] Seki Y, Kasama K, Tanaka T, Baba S, Ito M, Kurokawa Y. Early gastric cancer successfully treated by endoscopic submucosal resection 1 year after laparoscopic sleeve gastrectomy with duodenal-jejunal bypass. Asian J Endosc Surg. 2019;12:357-61. 